\title{
Microbiological profile and antibiotic sensitivity pattern in sputum cultures-A retrospective study
}

\author{
Sodani Sadhna ${ }^{1}$, Hawaldar Ranjana ${ }^{2, *}$ \\ ${ }^{\mathbf{1}}$ Assistant Professor, Dept. of Medical Microbiology, M. G. M, Medical College, Indore, Madhya Pradesh, ${ }^{2}$ Consultant \\ Pathologist, Dept. of Pathology, Sampurna Sodani Diagnostic Clinic, Indore, Madhya Pradesh, India
}

*Corresponding Author:

Email: drranjana@sampurnadiagnostics.com

\begin{abstract}
Introduction: Respiratory tract infections (RTI) are one of the most common cause of infections and are responsible for loss of working hours in affected individuals. Many newer antibiotics have been introduced to treat these infections whose sensitivity pattern is still not clearly understood due to paucity of published data in this regard:Several studies have been published in different parts of the world but still there are limited data from Indian subcontinent. The present retrospective study was carried out in microbiology department of our diagnostic centre with the aim of analyzing the various causative bacteria of CAP and to study their antibiotic sensitivity pattern.

Materials and Methods: The present retrospective study of sputum cultures was carried out between July to September 2017 in the microbiology department of our diagnostic centre. A total of 100 sputum samples collected from patients of all ages and both sexes were included in the study. Sputum samples were collected in wide mouth, sterile containers by standard protocols. Gram's staining and Zheil Neelsen staining for acid fast bacilli was done after inoculating the specimen on Blood and MacConkey Agar plates.

Results: There were 68 males and 32 females with a male to female ratio of $2.1: 1$. Maximum $23 \%$ patients were in $61-70$ years age group followed by $15 \%$ each in 41-50 and 51-60 years age group. 3\% patients were above 80 years of age. Normal bacterial flora was grown in $71 \%$ cases. Growth of pathogenic bacteria was observed in $29 \%$ cases. Klebsiella pneumoniae was the most commonly isolated micro-organism accounting for $13 \%$ cases. Staphylococcus aureus was isolated in $6 \%$ cases followed by Pseudomonas aeruginosa in $3 \%$ and $2 \%$ each of Enterococcus, E.coli and Candida species.

Conclusion: The role of sputum culture has for long been debatable and is limited by the fact that it is difficult to obtain a deep cough specimen in paediatric and geriatric patients .However, epidemiological value of sputum cultures as a tool in providing information about microbiological profile and antibiotic sensitivity pattern in different geographical areas of the world cannot be underestimated.
\end{abstract}

Keywords: Community acquired pneumonia, Chronic obstructive pulmonary disease, Sputum.

\section{Introduction}

Respiratory tract infections (RTI ) are one of the most common cause of infections and are responsible for loss of working hours in affected individuals .Among the RTI, pneumonia and chronic obstructive pulmonary disease (COPD) are common and prevalent in the community and cause significant morbidity and mortality .COPD is estimated to be the fourth leading cause of death in the world. ${ }^{1-3}$ Pneumonia is defined as infection of the lung parenchyma. ${ }^{4}$ It can be either community acquired (CAP) or nosocomial in origin.

Although community acquired pneumonia (CAP) is mostly bacterial in etiology but the causative organisms and their antibiotic sensitivity pattern varies from one region to another. The treatment of CAP is mostly empirical as patients tend to underestimate its potential complications and defer laboratory tests. ${ }^{5}$ All these factors have led to the emergence of resistant strains of common bacteria as well as emergence of newer bacteria causing CAP. Many newer antibiotics have been introduced to treat these infections whose sensitivity pattern is still not clearly understood due to paucity of published data in this regard. ${ }^{6}$ Several studies have been published in different parts of the world but still there are limited data from Indian subcontinent. ${ }^{7-11}$
Correct diagnosis of the causative microorganism depends on many factors including history of the patient, the clinical presentation and other laboratory investigations like X-Ray chest and sputum culture and Gram staining. However, there are inherent problems in the interpretation of these data as many times mixed flora as well as normal upper respiratory tract flora are isolated in culture due to inadequate and inappropriate sampling, which is mostly salivary in nature.

The present retrospective study was carried out in microbiology department of our diagnostic centre with the aim of analyzing the various causative bacteria of CAP and to study their antibiotic sensitivity pattern.

\section{Materials and Methods}

The present retrospective study of sputum cultures was carried out between July to September 2017 in the microbiology department of our diagnostic centre. A total of 100 sputum samples collected from patients of all ages and both sexes were included in the study. Patients with signs and symptoms of pneumonia like fever with chills, dyspnoea, cough, pleuritic chest pain and haemoptysis etc along with other supporting investigations like Chest Xray were included in the study. Patients who had received antibiotics prior to 
culture and hospitalized patients were excluded from the study. Diagnosis of pneumonia was presumptively made on the basis of history,signs and symptoms ,complete blood count ,ESR and chest radiograph.

Sputum samples were collected in wide mouth, sterile containers by standard protocols. When spontaneous expectoration was not possible, sputum was induced and collected. All sputum samples were then examined physically for appearance, volume, colour and presence of blood. Further Gram's staining and Zheil Neelsen staining for acid fast bacilli was done after inoculating the specimen on Blood and MacConkey Agar plates. The plates were then incubated at $37^{\circ} \mathrm{C}$ for 24 hours .After 24 hours, culture plates were observed for microbial growth. If growth was observed, Gram staining was done and identification and antibiotic sensitivity was done on Vitec II (Bio merieux)

\section{Results}

A total of 100 patients of all ages and both sexes were included in this retrospective study. The patients were divided into 0-10, 11-20, 21-30, 31-40, 41-50, 51$60,61-70,71-80$ and more than 80 years of age group in both sexes. There were 68 males and 32 females with a male to female ratio of 2.1:1. Maximum $23 \%$ patients were in $61-70$ years age group followed by $15 \%$ each in
41-50 and 51-60 years age group. 3\% patients were above 80 years of age. (Table 1 )

Normal bacterial flora was grown in $71 \%$ cases. Growth of pathogenic bacteria was observed in $29 \%$ cases. Klebsiella pneumoniae was the most commonly isolated micro-organism accounting for $13 \%$ cases. Staphylococcus aureus was isolated in $6 \%$ cases followed by Pseudomonas aeruginosa in 3\% and 2\% each of Enterococcus, E.Coli and Candida species and $1 \%$ case of Moraxella sps. (Table 2)

In the study of the antibiotic sensitivity pattern of microorganisms it was observed that E.Coli was sensitive to Amoxycillin/clavulinic acid, Piperacillin/Tazobactum, cefoxitin, Ertapenem, Amikacin, Gentamycin, Fosfomycin and Nitrofurantoin. Klebsiella was sensitive to Ertapenem and Gentamycin, Cefoperazone/Sulbactum, Imipenem,Meropenem,Tigecycline and Colistin while showing intermediate sensitivity to Piperacillin/Tazobactum. Pseudomonas showed sensitivity to Piperacillin/Tazobactum, Gentamycin and Ciprofloxacin as well as to Cefoperazone/sulbactum, Cefipime, Imipenem, Meropenem and Colistin. Enterococcus sps was sensitive to most of the antibiotics while showing intermediate sensitivity to Erythromycin and resistance to Clindamycin. Staph aureus was sensitive to most of the antibiotics as per the CLSI guidelines and showed resistance to Amoxycillin, Erythromycin and Benzylpenicillin. (Table 3)

Table 1: Showing demographic data of patients

\begin{tabular}{|l|c|c|c|}
\hline \multicolumn{1}{|c|}{ Age } & Male & Female & Total \\
\hline $0-10$ & 4 & 0 & 4 \\
\hline 11 to 20 & 2 & 3 & 5 \\
\hline 21 to 30 & 7 & 6 & 13 \\
\hline 31 to 40 & 10 & 4 & 14 \\
\hline 41 to 50 & 8 & 7 & 15 \\
\hline 51 to 60 & 10 & 5 & 15 \\
\hline 61 to 70 & 18 & 5 & 23 \\
\hline 71 to 80 & 7 & 1 & 8 \\
\hline$>80$ & & & \\
\hline Total & 68 & 32 & 100 \\
\hline
\end{tabular}




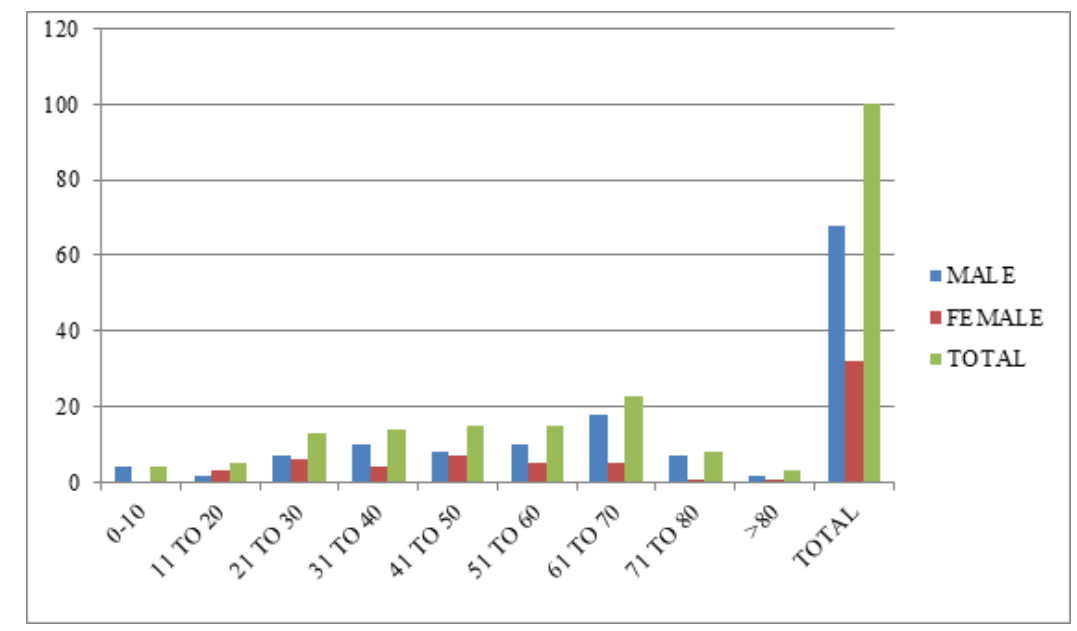

Fig. 1

Table 2

\begin{tabular}{|l|l|l|l|l|l|l|l|l|l|}
\hline Age & $\begin{array}{l}\text { Normal } \\
\text { flora }\end{array}$ & Klebsiella & E.coli & $\begin{array}{l}\text { Entero- } \\
\text { coccus }\end{array}$ & $\begin{array}{l}\text { Pseudo- } \\
\text { monas }\end{array}$ & Moraxella & $\begin{array}{l}\text { Staph. } \\
\text { aureus }\end{array}$ & Candida & Total \\
\hline 0 to 10 & 2 & 1 & & & & & 1 & & \\
\hline 11 to 20 & 5 & & & & & & & & \\
\hline 21 to 30 & 9 & & & & 1 & & 3 & & \\
\hline 31 to 40 & 11 & 2 & & & & 1 & & & \\
\hline 41 to 50 & 13 & 1 & & & & & & 1 & \\
\hline 51 to 60 & 11 & 1 & & & 1 & & 1 & 1 & \\
\hline 61 to 70 & 13 & 4 & 1 & & 1 & & 1 & & \\
\hline 71 to 80 & 5 & 3 & 1 & 1 & & & & & \\
\hline$>80$ & 2 & 1 & 0 & 1 & & & & & 4 \\
\hline Total & 71 & 13 & 2 & 2 & 3 & 1 & 6 & 2 & 100 \\
\hline
\end{tabular}

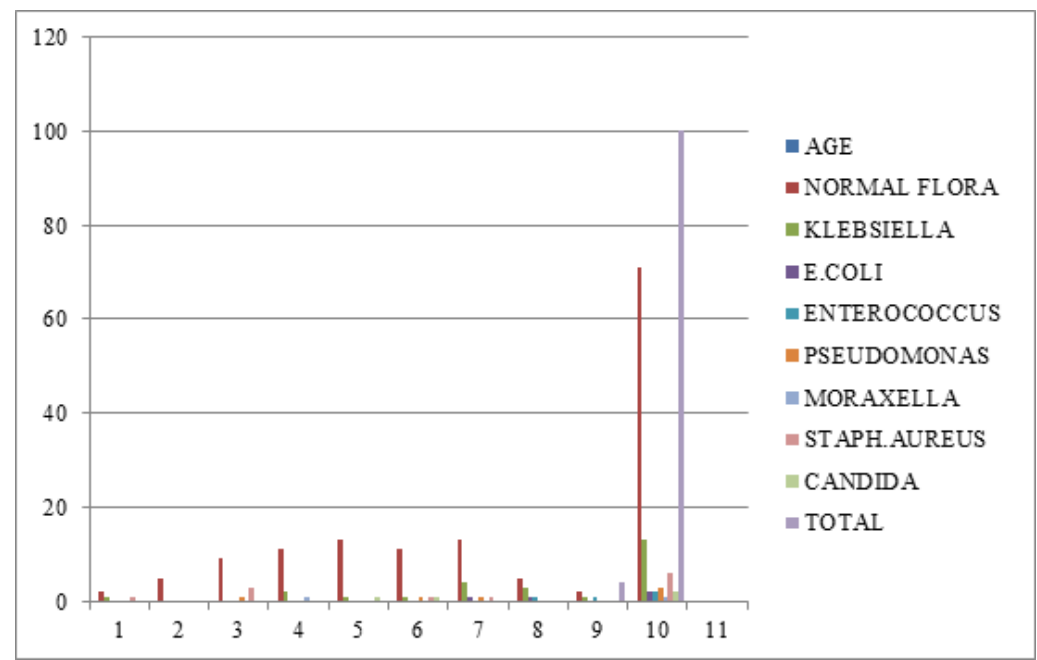

Fig. 2: Showing bacterial growth 
Table 3: Showing antibiotic sensitivity pattern

\begin{tabular}{|c|c|c|c|c|c|c|c|c|c|c|}
\hline \multirow[t]{2}{*}{ Antibiotic } & \multicolumn{2}{|c|}{ E. Coli } & \multicolumn{2}{|c|}{$\begin{array}{c}\text { Staph } \\
\text { aureus }\end{array}$} & \multicolumn{2}{|c|}{ Pseudomonas } & \multicolumn{2}{|c|}{ Enterococus } & \multicolumn{2}{|c|}{ Klebsiella } \\
\hline & MIC & & MIC & & MIC & & MIC & & MIC & \\
\hline Ampicilin & $>=32$ & $\mathbf{R}$ & & & $>=32$ & $\mathrm{R}$ & & & & \\
\hline $\begin{array}{l}\text { Amoxicillin/ } \\
\text { Clavulanic }\end{array}$ & 4 & $\mathrm{~S}$ & & & $>=32$ & $\mathrm{R}$ & & & & \\
\hline Ticarcillin & $>=128$ & $\mathrm{R}$ & & & & & & & & \\
\hline $\begin{array}{l}\text { Piperacillin/ } \\
\text { Tazobactam }\end{array}$ & $<=4$ & $\mathrm{~S}$ & & & 8 & $\mathrm{~S}$ & & & 32 & I \\
\hline Cefalotin & $>=64$ & $\mathrm{R}$ & & & $>=64$ & $\mathrm{R}$ & & & & \\
\hline Cefoxitin & $<=4$ & $\mathrm{~S}$ & & & & & & & & \\
\hline Cefixime & $>=4$ & $\mathrm{R}$ & & & & & & & & \\
\hline Ceftazidime & 4 & $* \mathrm{R}$ & & & & & & & & \\
\hline Ceftriaxone & $>=64$ & $\mathrm{R}$ & & & $>=64$ & $\mathrm{R}$ & & & $>=64$ & $\mathrm{R}$ \\
\hline Ertapenem & $<=0.5$ & $\mathrm{~S}$ & & & & & & & $<=0.5$ & $\mathrm{~S}$ \\
\hline Amikacin & $<=2$ & $\mathrm{~S}$ & & & $<=2$ & & & & 8 & $\mathrm{~S}$ \\
\hline Gentamicin & $<=1$ & $\mathrm{~S}$ & $<=0.5$ & $\mathrm{~S}$ & $<=1$ & $S$ & & & $>=16$ & $\mathrm{R}$ \\
\hline Nalidixic Acid & $>=32$ & $\mathrm{R}$ & & & $>=32$ & $\mathrm{R}$ & & & & \\
\hline Ciprofloxacin & $>=4$ & $\mathrm{R}$ & 1 & $\mathrm{~S}$ & $<=0.25$ & $\mathrm{~S}$ & 1 & $\mathrm{~S}$ & $>=4$ & $\mathrm{R}$ \\
\hline Norfloxacin & $>=16$ & $\mathrm{R}$ & & & & & & & & \\
\hline Ofloxacin & $>=8$ & $\mathrm{R}$ & & & & & & & & \\
\hline Fosfomycin & $<=16$ & $\mathrm{~S}$ & & & & & & & & \\
\hline Nitrofurantoin & $<=16$ & $\mathrm{~S}$ & & & 256 & $\mathrm{R}$ & $<=16$ & $\mathrm{~S}$ & & \\
\hline $\begin{array}{l}\text { Trimethoprim/ } \\
\text { Sulfamethoxazole }\end{array}$ & $>=320$ & $\mathrm{R}$ & 20 & $\mathrm{~S}$ & 160 & $\mathrm{R}$ & & & $>=320$ & $\mathrm{R}$ \\
\hline $\begin{array}{l}\text { Amoxicillin/ } \\
\text { Clavulanic Acid }\end{array}$ & & & & & $>=32$ & $\mathrm{R}$ & & $\mathrm{S}$ & $>=32$ & $\mathrm{R}$ \\
\hline Cefuroxime & & & & & $>=64$ & $\mathrm{R}$ & & & $>=64$ & $\mathrm{R}$ \\
\hline $\begin{array}{l}\text { Cefuroxime } \\
\text { Axetil }\end{array}$ & & & & & $>=64$ & $\mathrm{R}$ & & & $>=64$ & $\mathrm{R}$ \\
\hline $\begin{array}{l}\text { Cefoperazone/ } \\
\text { Sulbactam }\end{array}$ & & & & & $<=8$ & $S$ & & & 16 & $S$ \\
\hline Cefepime & & & & & 4 & $\mathrm{~S}$ & & & 32 & $\mathrm{R}$ \\
\hline Imipenem & & & & & 2 & $\mathrm{~S}$ & & & $<=0.25$ & $\mathrm{~S}$ \\
\hline Meropenem & & & & & 1 & $\mathrm{~S}$ & & & $<=0.25$ & $\mathrm{~S}$ \\
\hline Tigecycline & & & & & 4 & $* \mathrm{R}$ & $<=0.12$ & $\mathrm{~S}$ & 1 & $\mathrm{~S}$ \\
\hline Colistin & & & & & $<=0.5$ & $S$ & & & $<=0.5$ & $\mathrm{~S}$ \\
\hline Benzylpenicillin & & & & & & & 0.25 & $\mathrm{~S}$ & & \\
\hline Amoxicillin & & & & $\mathrm{R}$ & & & & $\mathrm{S}$ & & $\mathrm{R}$ \\
\hline Ampicillin & & & & & & & & $\mathrm{S}$ & $>=32$ & $\mathrm{R}$ \\
\hline $\begin{array}{l}\text { Ampicillin/ } \\
\text { Sulbactam }\end{array}$ & & & & & & & & $\mathrm{S}$ & & \\
\hline $\begin{array}{l}\text { Gentamicin } \\
\text { High Level } \\
\text { (synergy) }\end{array}$ & & & & & & & SYN-S & $\mathrm{S}$ & & \\
\hline Levofloxacin & & & 2 & $S$ & & & 2 & $S$ & & \\
\hline Inducible & & & & & & & & & & \\
\hline
\end{tabular}




\begin{tabular}{|l|l|l|l|l|l|l|l|l|l|l|}
\hline $\begin{array}{l}\text { Cindamycin } \\
\text { Resistance }\end{array}$ & & & & & & & & & & \\
\hline Erythromycin & & & $2^{*}$ & $* \mathrm{R}$ & & & 2 & $\mathrm{I}$ & & \\
\hline Clindamycin & & & $<=0.12$ & $\mathrm{~S}$ & & & $<=0.12$ & $* \mathrm{R}$ & & \\
\hline Linezolid & & & 2 & $\mathrm{~S}$ & & & 1 & $\mathrm{~S}$ & & \\
\hline Teicoplanin & & & $<=0.5$ & $\mathrm{~S}$ & & & $<=0.5$ & $\mathrm{~S}$ & & \\
\hline Vancomycin & & & $<=0.5$ & $\mathrm{~S}$ & & & $<=0.5$ & $\mathrm{~S}$ & & \\
\hline Tetracycline & & & 2 & $\mathrm{~S}$ & & & 2 & $\mathrm{~S}$ & & \\
\hline Cefotaxime & & & & & & & & & & $\mathrm{R}$ \\
\hline Benzylpenicillin & & & 0.25 & $\mathrm{R}$ & & & & & & \\
\hline Rifampicin & & & $<=0.03$ & $\mathrm{~S}$ & & & & & & \\
\hline
\end{tabular}

\section{Discussion}

Due to use of broad spectrum antibiotics in the therapy of Community acquired pneumonia in the early stage of the disease, these infections are now becoming less common. This is possibly attributed to increasing awareness about personal health, availability of better and affordable health care and diagnostic facilities and knowledge among general population about the implications of these diseases if left untreated for long. In our study $29 \%$ patients showed growth of pathogenic bacteria in sputum culture out of which $23 \%$ patients were in 61-70 years age group. Acharya V. et al in their study of 100 patients observed that 64 were males and 36 were females. In their study positivity rate of sputum culture was $39 \% .{ }^{12}$ Most of their patients were above 40 years of age. Similarly, our study also correlates with the study by Shah et al who observed pneumonia to be common in patients above 40 years of age. ${ }^{13}$ In the study by Gupta et al and according to National pneumonia guidelines, yield of sputum cultures varies from $34 \%$ to as high as $86 \%$. ${ }^{(14)}$ In the study by Vesna Cukic et al $58.5 \%$ patients showed normal nonpathogenic bacterial growth in sputum cultures ${ }^{\left({ }^{15)}\right.}$ In their study Streptococcus pneumoniae was isolated in 7 patients, Klebsiella in 8 and E.coli in 4 patients.

Choosing proper antibiotics to treat CAP is crucial for a good clinical outcome. The antibiotics chosen should have broad spectrum coverage with low antimicrobial resistance. Woodhead et al in their study found that Beta lactam antibiotics, macrolides and fluoroquinolones were very effective in non severe form of $\mathrm{CAP}^{(16)}$ In the study by Acharya et al a good sensitivity was observed to third generation cephalosporins and macrolides or in combination. ${ }^{12}$ They found increasing sensitivity to beta lactam inhibitors. In our study, only E.coli was sensitive to Fosfomycin. Pseudomonas was sensitive to injectable antibiotics while Enterococcus and Staph aureus were sensitive to most of the commonly prescribed antibiotics.

\section{Conclusion}

The role of sputum culture has for long been debatable and is limited by the fact that it is difficult to obtain a deep cough specimen in paediatric and geriatric patients and there is always a possibility of contamination by normal upper respiratory tract flora which poses problems in culturing the specimen and therefore has direct and indirect effect on treatment decisions and clinical outcome of the patients. ${ }^{17-23}$ However, these problems can be overcome to a large extent by Gram stain of sputum which is highly specific for the preliminary diagnosis of CAP and in guiding antimicrobial therapy till culture results are available. However, epidemiological value of sputum cultures as a tool in providing information about microbiological profile and antibiotic sensitivity pattern in different geographical areas of the world cannot be underestimated.

\section{Conflict of Interest: None}

\section{References}

1. GOLD (Global Initiative for Chronic Obstructive Lung Disease)-global strategy for the diagnosis, management, and prevention of chronic obstructive pulmonary diseaserevised. http://www.goldcopd.org .2006. pp. 1-100.

2. World Health Report. Geneva: World Health Organization; 2000.

http://www.who.int/whr/2000/en/statistics.htm .

3. Lopez AD, Shibuya K, Rao C, Mathers CD, Hansell $\mathrm{AL}$, et al. Chronic obstructive pulmonary disease: current burden and future projections. Eur Respir J. 2006;27(2):397-412.

4. Deshpande Alaka. Epidemiology of community acquired pneumonia. JAPI. 2012;60:S6.

5. Mandella LA. Epidemiology and etiology of community-acquired pneumonia. Infect Dis Clin North Am. 2002;18:761-76.

6. Al-Ali MK, Batchoun RG, Al-Nour TM. Etiology of community-acquired pneumonia in hospitalized patients in Jordan. Saudi Med J. 2006;27:813-6.

7. Reechaipichitkul W, Lulitanond V, Tantiwong P, Saelee R, Pisprasert V. Etiologies and treatment outcomes in patients hospitalized with communityacquired pneumonia at Srinagarind Hospital, 
KhonKaen, Thailand. Southeast Asian J Trop Med Public Health. 2005;36:156-61.

8. Niederman MS. Review of treatment guidelines for community-acquired pneumonia. Am J

Med. 2004;117(Suppl 3A):1-7.

9. Riquelme O R, Riquelme O M, Riquelme O M, Rioseco Z ML, Gomez M V, Gil D R. Etiology and prognostic factors of community-acquired pneumonia among adult patients admitted to a regional hospital in Chile. Rev Med Chil. 2006;134:597-605.

10. Bansal S, Kashyap S, Pal LS, Goel A. Clinical and bacteriological profile of community-acquired pneumonia in Shimla, Himachal Pradesh. Indian J Chest Dis Allied Sci. 2004;46:17-22.

11. Djukanovic R, Sterk PJ, Fahy JV, Hargreave FE. Standardised methodology of sputum induction and processing. EurRespir J. 2002;20:19-39.

12. Vishak K Acharya Mahesha Padyana, Microbiological Profile and Drug Sensitivity Pattern among Community Acquired Pneumonia Patients in Tertiary Care Centre in Mangalore, Coastal Karnataka, India J Clin Diagn Res. 2014 Jun;8(6):MC04-MC06.

13. Shah PB, Giudice JC, Griesback R, Morley TF, Vasoya $\mathrm{A}$. The newer guidelines for the management of community acquired pneumonia. JAOA. 2004;104:521-6.

14. Gupta D, Agarwal R, Aggarwal AN, Singh N, Mishra N, Khilnani GC, et al. Guidelines for diagnosis and management of community- and hospital-acquired pneumonia in adults: Joint ICS / NCCP (I) recommendations. Lung India. 2010:S27-67.

15. Vesna Cukic The Most Common Detected Bacteria in Sputum of Patients with the Acute Exacerbation of COPDMater Sociomed. 2013 Dec; 25(4): 226-9.

16. Woodhead M, Verheij T. Commentary: A step forward in everyday management of adults with community. BMJ. 2005;330:460.

17. Gleckman R, DeVita J, Hibert D, Pelletier C, Martı'n R. Sputum gram stain assessment in communityacquired pneumonia. J Clin Microbiol. 1988;26:846-9.

18. 18.. Fine MJ, Orloff JJ, Rihs JD, et al. Evaluation of housestaff physicians' preparation and interpretation of sputum Gram stains for community-acquired pneumonia. J Gen Intern Med. 1991;6:189-98.

19. 19.. Roson B, Carratala J, Verdaguer R, Dorca J, Manresa F, Gudiol F. Prospective study of the usefulness of sputum Gram stain in the initial approach to communityacquired pneumonia requiring hospitalization. Clin Infect Dis. 2000;31:347-382.

20. 20. Ewig S, Schlochtermeier M, Go“ke N, Niederman M. Applying sputum as a diagnostic tool in pneumonia. Chest. 2002;121:1486-92.

21. 21. Cordero E, Pacho'n J, Rivero A, et al. Usefulness of sputum culture for diagnosis of bacterial pneumonia in HIV infected patients. Eur J Clin Microbiol Infect Dis. 2002;21:362-7.

22. 22. Belliveau P, Hickingbotham N, Maderazo EG, Mazens-Sullivan M, Robinson A. Institution-specific patterns of infection and Gram's stain as guides for empiric treatment of patients hospitalized with typical community-acquired pneumonia. Pharmacotherapy. 1993; 13:396-401.

23. 23. Bohte R, Hermans J, van den Broek PJ. Early recognition of Streptococcus pneumoniae in patients with community acquired pneumonia. Eur J Clin Microbiol Infect Dis. 1996;15:201-5.
How to cite this article: Sadhna $\mathrm{S}$, Ranjana $\mathrm{H}$. Microbiological profile and antibiotic sensitivity pattern in sputum cultures-A retrospective study. Indian $\mathbf{J}$ Microbiol Res 2018;5(1):100-105. 